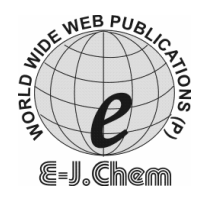

http://www.e-journals.net
ISSN: 0973-4945; CODEN ECJHAO

E-Journal of Chemistry

2009, 6(4), 1091-1102

\title{
Development and Validation of a Rapid RP-HPLC Method for the Determination of Venlafaxine Hydrochloride in Pharmaceutical Dosage forms using Experimental Design
}

\author{
VANITA SOMASEKHAR $^{\S *}$, DANNANA GOWRISANKAR and H.N.SHIVAKUMAR ${ }^{\S}$ \\ ${ }^{\S}$ K.L.E Society's College of Pharmacy, \\ II Block, Rajajinagar, Bangalore - 560 010, India. \\ College of Pharmaceutical Sciences, Andhra University, \\ Visakhapatnam - 530 003, India. \\ vanitasom@gmail.com
}

Received 28 January 2009; Accepted 25 March 2009

\begin{abstract}
The objective of the current study was to develop a simple, accurate, precise and rapid reversed-phase HPLC method and subsequent validation as per ICH guidelines for the determination of venlafaxine hydrochloride in pharmaceutical dosage forms. The proposed RP-HPLC method utilizes a $5 \mu \mathrm{m}$ Varian ${ }^{\circledR}$ MicrosorbMV $100 \mathrm{C}_{18}$ column $(250 \mathrm{~mm} \times 4.6 \mathrm{~mm})$ at ambient temperature. A $2^{3}$ factorial design consisting of 3 factors at 2 levels was set up to standardize the chromatographic conditions. A numerical optimization technique employing the desirability approach was used to locate the optimum chromatographic conditions. The optimum mobile phase consisted of acetonitrile, $0.04 \mathrm{M}$ potassium dihydrogen phosphate buffer and methanol (45:25:30, v/v), with $\mathrm{pH}$ adjusted to 5.5 using $10 \%$ phosphoric acid solution. The mobile phase was delivered isocratically at a flow rate of $1 \mathrm{~mL} / \mathrm{min}$ with UV detection at $224 \mathrm{~nm}$. The calibration plots constructed using the optimized chromatographic conditions displayed good linear relationship in the concentration range of $1-50 \mu \mathrm{g} / \mathrm{mL}$ with $\mathrm{r}=0.9992$. The method was validated for precision, accuracy, robustness and recovery. The minimum detectable and minimum quantifiable amounts were found to be 0.568 and 1.72 $\mu \mathrm{g} / \mathrm{mL}$, respectively and the method was found to be reproducible from the statistical data generated. Venlafaxine hydrochloride was eluted at $3.43 \mathrm{~min}$.
\end{abstract}

Keywords: Venlafaxine hydrochloride, Reversed-phase HPLC, Experimental design, Validation.

\section{Introduction}

Venlafaxine hydrochloride Figure 1, (1-[2-dimethylamino)-1-(4-methoxy phenyl) ethyl] cyclohexanol) hydrochloride is a third generation antidepressant ${ }^{1,2}$. It inhibits the reuptake of 
serotonin, norepinephrine and to a lesser extent dopamine ${ }^{3-5}$. It lacks monoamine oxidase activity and more importantly, the adverse effect profile of tricyclic antidepressants ${ }^{1,3}$. Venlafaxine has no affinity for brain muscarinic, cholinergic, histaminergic or adrenergic receptors ${ }^{1,6}$. Various HPLC methods are reported in literature for the analysis of venlafaxine. However, most HPLC methods cited $^{7-14}$ are useful in estimating venlafaxine in human plasma, serum and biological fluids. The same have not been applied for estimation of venlafaxine hydrochloride in pharmaceutical formulations, which have various kinds of excipients. Very few papers have come out with methods that have been applied for estimation of venlafaxine hydrochloride in pharmaceutical formulations ${ }^{15-17}$.

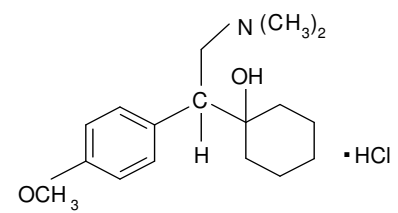

Figure 1. Chemical structure of venlafaxine hydrochloride.

Hence, in the present study, an attempt has been made to develop an accurate, rapid and precise HPLC method with isocratic elution for determination of venlafaxine in pharmaceutical formulations. The developed method was validated and used for the assay of venlafaxine hydrochloride in capsules and tablets.

\section{Experimental}

Venlafaxine hydrochloride was a gift sample from Lupin Ltd., Pune, India. VENLIFT OD37.5 and VENLOR-XR 75 were marketed samples of Torrent Pharmaceuticals Ltd., India and Protec, India, respectively. Acetonitrile, methanol, potassium dihydrogen phosphate and sodium hydroxide of Rankem used were of HPLC grade. Ortho-phosphoric acid used was of analytical reagent grade and was purchased from S.D. Fine Chemicals Ltd., Mumbai, India. Experiments were conducted with ultra pure water obtained from Milli-Q academic system (Millipore Pvt. Ltd., Bangalore, India).

\section{HPLC instrumentation and conditions}

The HPLC system consisted of Hitachi pump L-7110, Rheodyne universal injector 7725 and Hitachi L-7400 UV-visible detector. The chromatographic studies were performed using Varian ${ }^{\circledR}$ Microsorb-MV $100 \mathrm{C}_{18}, 5 \mu \mathrm{m}, 250 \mathrm{~mm} \times 4.6 \mathrm{~mm}$ i.d. column, at ambient temperature and eluted with mobile phase at the flow rate of $1.0 \mathrm{~mL} / \mathrm{min}$. The mobile phase consisted of acetonitrile, $0.04 \mathrm{M}$ potassium dihydrogen phosphate buffer and methanol (45:25:30, v/v), with $\mathrm{pH}$ adjusted to 5.5 with $10 \%$ phosphoric acid solution and was delivered isocratically at a flow rate of $1 \mathrm{~mL} / \mathrm{min}$. The mobile phase was filtered through $0.45 \mu \mathrm{m}$ nylon filter and degassed in ultrasonic bath prior to use. Absorption maximum was detected by scanning standard solution of the drug over 200 to $400 \mathrm{~nm}$ wavelengths in Shimadzu model 1700 double beam UV-visible spectrophotometer with a pair of $10 \mathrm{~mm}$ matched quartz cells. Measurements were made with injection volume of $20 \mu \mathrm{L}$ and at a wavelength of $224 \mathrm{~nm}$ using an ultraviolet (UV) detector.

\section{Experimental design}

An 8-run, $2^{3}$ factorial design consisting of 3 factors at 2 levels was set up to standardize the chromatographic conditions which are likely to be employed. Percentage of methanol in the organic phase $\left(\mathrm{X}_{1}\right)$, proportion of buffer in the mobile phase $\left(\mathrm{X}_{2}\right)$ and $\mathrm{pH}$ of the mobile phase $\left(X_{3}\right)$ as per $2^{3}$ factorial design are represented in Table 1 . By varying $X_{1}, X_{2}$ and $X_{3}$, a total of eight runs were performed as represented in Table 2. 
Table 1. Factors and their corresponding levels as per $2^{3}$ factorial design.

\begin{tabular}{|c|c|c|}
\hline Independent Factors & Low level & High level \\
\hline $\begin{aligned} \mathrm{X}_{1}: & \text { Percentage of methanol in } \\
& \text { organic phase }\end{aligned}$ & 20 & 80 \\
\hline $\begin{array}{l}\mathrm{X}_{2}: \text { Proportion of buffer in } \\
\text { mobile phase }\end{array}$ & 25 & 75 \\
\hline $\mathrm{X}_{3}: \mathrm{pH}$ & 4.0 & 5.5 \\
\hline Dependent Factors & \multicolumn{2}{|c|}{ Constraints } \\
\hline $\mathrm{Y}_{1}$ : Retention Time & \multicolumn{2}{|c|}{ Above 3.0} \\
\hline $\mathrm{Y}_{2}:$ Tailing Factor & \multicolumn{2}{|c|}{ Minimize } \\
\hline
\end{tabular}

Table 2. Chromatographic conditions employed as per $2^{3}$ factorial design

\begin{tabular}{cccc}
\hline Run & $\begin{array}{c}\text { \% of methanol in organic } \\
\text { phase }\end{array}$ & $\begin{array}{c}\text { Proportion of buffer in } \\
\text { mobile phase }\end{array}$ & $\mathrm{pH}$ \\
\hline R1 & 20 & 25 & 4.0 \\
R2 & 80 & 25 & 4.0 \\
R3 & 20 & 75 & 4.0 \\
R4 & 80 & 75 & 4.0 \\
R5 & 20 & 25 & 5.5 \\
R6 & 80 & 25 & 5.5 \\
R7 & 20 & 75 & 5.5 \\
R8 & 80 & 75 & 5.5 \\
\hline
\end{tabular}

\section{Preparation of standard solutions}

Stock standard solution of venlafaxine hydrochloride was prepared by dissolving appropriate amounts in methanol to give a final concentration of $1000 \mu \mathrm{g} / \mathrm{mL}$. Standard solutions of venlafaxine hydrochloride $(1.0,2.5,5.0,10.0,20.0,30.0,40.0,50.0 \mu \mathrm{g} / \mathrm{mL})$ were prepared by subsequent dilution with mobile phase.

\section{Regression analysis}

The targeted response parameters were statistically analyzed by applying one-way ANOVA at 0.05 levels in Design-Expert 7.1 demo version software (Stat-Ease Inc., Minneapolis, MN, USA). The individual parameters were evaluated using the F test and mathematical models of the form indicated in $\mathrm{Eq}$ (1) were generated for each response:

$$
Y=\beta_{0}+\beta_{1} X_{1}+\beta_{2} X_{2}+\beta_{3} X_{3}+\beta_{4} X_{1} X_{2}+\beta_{5} X_{2} X_{3}+\beta_{6} X_{1} X_{3}+\beta_{7} X_{1} X_{2} X_{3}
$$

where, $Y$ is the level of the measured response, $\beta_{0}$ is the intercept, $\beta_{1}$ to $\beta_{7}$ are the regression coefficients, $X_{1}, X_{2}$ and $X_{3}$ stand for the main effects, $X_{1} X_{2}, X_{2} X_{3}$ and $X_{1} X_{3}$ are the two-way interactions between the main effects and $X_{1} X_{2} X_{3}$ is the three-way interaction between the main effects. The polynomial models containing only the significant terms $(\mathrm{P}<0.05)$ were generated for each response parameter using multiple linear regression analysis (MLRA) and analysis of variance (ANOVA). Since the ratio of the highest and lowest value for the Tailing Factor was more than 3, a log transformation was performed as indicated by the Box-cox diagnostic plot available in the software. The models generated were used to construct the 3-dimensional graphs in which response parameter $\mathrm{Y}$ was represented as a function of $\mathrm{X}$. The effect of independent variables on each response was also visualized from the contour plots. 


\section{Verification of the mathematical models and optimization}

A numerical optimization technique employing the desirability approach was used to locate the optimum chromatographic conditions for the method developed and hence to verify the mathematical models generated. Various feasibility and grid searches were executed to establish the optimum chromatographic conditions for the method employed. Constraints set on each factor to locate the optimum chromatographic conditions are listed in Table 1. The optimized conditions as per Table 3 were employed and evaluated for the responses. The experimental values of retention time and tailing factor were compared with those predicted by the mathematical models.

Table 3. Experimental values for the retention time and the tailing factor.

\begin{tabular}{ccc}
\hline Run & Retention time & Tailing factor \\
\hline R1 & 3.24 & 1.33 \\
R2 & 3.29 & 1.55 \\
R3 & 3.51 & 4.0 \\
R4 & 2.72 & 2.5 \\
R5 & 3.44 & 1.21 \\
R6 & 3.47 & 1.44 \\
R7 & 3.48 & 2.0 \\
R8 & 2.68 & 1.34 \\
\hline
\end{tabular}

\section{Validation}

Three series of standard calibration solutions in the range of $1.0-50.0 \mu \mathrm{g} / \mathrm{mL}$ were prepared and analyzed as described above. Calibration curves were constructed by plotting the measured peak area of venlafaxine hydrochloride versus concentrations of standard samples.

To establish the accuracy and intra-day and inter-day precision of the method, three replicate standard solutions at three different concentrations $(1.0,10.0$ and $50.0 \mu \mathrm{g} / \mathrm{mL}$ ) were assayed on single day and three separate days.

\section{Analysis of dosage forms}

The content of 20 capsules were combined and weighed. An amount of powder equivalent to $100 \mathrm{mg}$ of venlafaxine hydrochloride was accurately weighed, transferred to a $100 \mathrm{~mL}$ volumetric flask, made up to volume with methanol and placed in an ultrasonic bath for 20 min. After filtration through a $0.45 \mu \mathrm{m}$ membrane filter, the solution was diluted with mobile phase to obtain a concentration of $20 \mu \mathrm{g} / \mathrm{mL}$. The drug concentrations of three parallels were determined by HPLC using the calibration curve.

\section{Results and Discussion}

\section{Chromatographic conditions}

Potassium dihydrogen phosphate buffer in the concentration range 0.025 to $0.075 \mathrm{M}$ was studied and $0.04 \mathrm{M}$ was selected as it gave shorter retention time with minimum tailing factor.

A $2^{3}$ factorial design was employed to prepare the mobile phase using potassium dihydrogen phosphate buffer $(0.04 \mathrm{M})$. A set of preliminary studies were undertaken to establish the range of each variable with the aim of fine-tuning the chromatographic peaks. Since lower $\mathrm{pH}$ values have a deteriorating effect on silica based columns ${ }^{18}$ and $\mathrm{pH}$ values above 5.5 resulted in broad peaks with significant tailing, the lower and higher levels of $\mathrm{pH}$ during the runs were maintained at 4.0 and 5.5. Decreasing proportion of buffer in mobile 
phase to less than $25 \%$ decreased retention time to a value such that the drug peak merged with the solvent peak, while increasing buffer proportion to more than $75 \%$ substantially increased retention time making the analysis time too long. Hence the lower and higher levels of proportion of buffer in mobile phase were maintained at 25 and $75 \% \mathrm{v} / \mathrm{v}$. Decreasing methanol percentage in organic phase to less than $20 \%$ increased tailing drastically while $100 \%$ methanol in organic phase increased retention time. Hence the lower and higher levels of percentage of methanol in the organic phase were maintained at 20 and $80 \% \mathrm{v} / \mathrm{v}$ respectively.

The results of analysis of variance and mathematical models generated by regressional analysis are represented in Table 4 . The Fisher $\mathrm{F}$ test indicated that all the mathematical models generated for the response parameters were found to be significant $(\mathrm{P}>\mathrm{F}$ less than 0.05). The primary statistical tool for identifying the need for transformations and for pinpointing which one works best is the Box-cox plot $^{19}$. The transformation was performed as indicated by the diagnostic plot. The predictor model generated for the Tailing Factor upon transformation was found to be significant. The polynomial models constitute the coefficients for the intercept, first order main effects and interaction effects. The sign and magnitude of the main effects signify the relative influence of each factor on the response.

Regression equations of the fitted model:

$$
\begin{aligned}
Y_{1} & =2.152+0.007 X_{1}+0.023 X_{2}+0.202 X_{3}-0.0003 X_{1} X_{2}-0.003 X_{2} X_{3} \\
\log _{10} Y_{2} & =-0.417+0.003 X_{1}+0.024 X_{2}+0.059 X_{3}-0.00008 X_{1} X_{2}-0.003 X_{2} X_{3}
\end{aligned}
$$

Table 4. Summary of ANOVA for the response parameters of the model mobile phases prepared as per $2^{3}$ factorial design

\begin{tabular}{cccccc}
\hline Response & F value & Prob $>\mathrm{F}$ & $\mathrm{R}^{2}$ & Adj R $^{2}$ & \%RSD \\
\hline $\mathrm{Y}_{1}$ & 2588.04 & 0.0004 & 0.9998 & 0.9995 & 0.24 \\
$\mathrm{Y}_{2}$ & 352.49 & 0.0028 & 0.9989 & 0.9960 & 4.50 \\
\hline
\end{tabular}

The Fisher F test with a very low probability value $(\mathrm{P}>\mathrm{F}=0.0004)$ demonstrated a very high significance of the predictor model generated for the Retention Time $\left(\mathrm{Y}_{1}\right)$. The goodness of fit of the model was checked by the adjusted determination coefficient (adjusted $R^{2}$ ). The determination coefficient $\left(R^{2}\right)$ is a measure of the amount of reduction of variability of $\mathrm{Y}$ obtained using the regressor variables $\mathrm{X}_{1}, \mathrm{X}_{2}$ and $\mathrm{X}_{3}$. If insignificant terms were to be included in the model the adjusted $R^{2}$ value tends to decrease ${ }^{20}$. The adjusted $R^{2}$ value approached unity as the model was refined by removing the insignificant variables. The value of the determination coefficient $\left(\mathrm{R}^{2}=0.9998\right)$ was in reasonable agreement with the adjusted determination coefficient (adjusted $R^{2}=0.9995$ ), which confirmed the high significance of the model. A relatively low value of relative standard deviation $(\% \mathrm{RSD}=$ $0.24)$ confirmed the improved precision and reliability of the conducted trials ${ }^{20}$. The polynomial model generated for the Retention Time indicated that the percentage of methanol in the organic phase $(\mathrm{P}>\mathrm{F}=0.0002)$, the proportion of buffer in the mobile phase $(\mathrm{P}>\mathrm{F}=0.0005)$ and the $\mathrm{pH}$ of the mobile phase $(\mathrm{P}>\mathrm{F}=0.0052)$, had significant positive influence on $\mathrm{Y}_{1}$. In addition to the main effects, the interaction terms $\mathrm{X}_{1} \mathrm{X}_{2}(\mathrm{P}>\mathrm{F}=0.0002)$ and $\mathrm{X}_{2} \mathrm{X}_{3}(\mathrm{P}>\mathrm{F}=0.0025)$ also had significant negative influence on $\mathrm{Y}_{1}$.

The combined influence of $\mathrm{X}_{1}$ and $\mathrm{X}_{2}$ on $\mathrm{Y}_{1}$ is shown by the 3-dimensional plot represented in Figure 2A. The pattern of the contours (Figure 2B) reflects a significant interaction between the two variables analyzed, particularly at higher buffer proportions in the mobile phase. The plots clearly indicate that a retention time within the experimental constraints can be obtained using lower and intermediate percentage of methanol in the organic phase. 

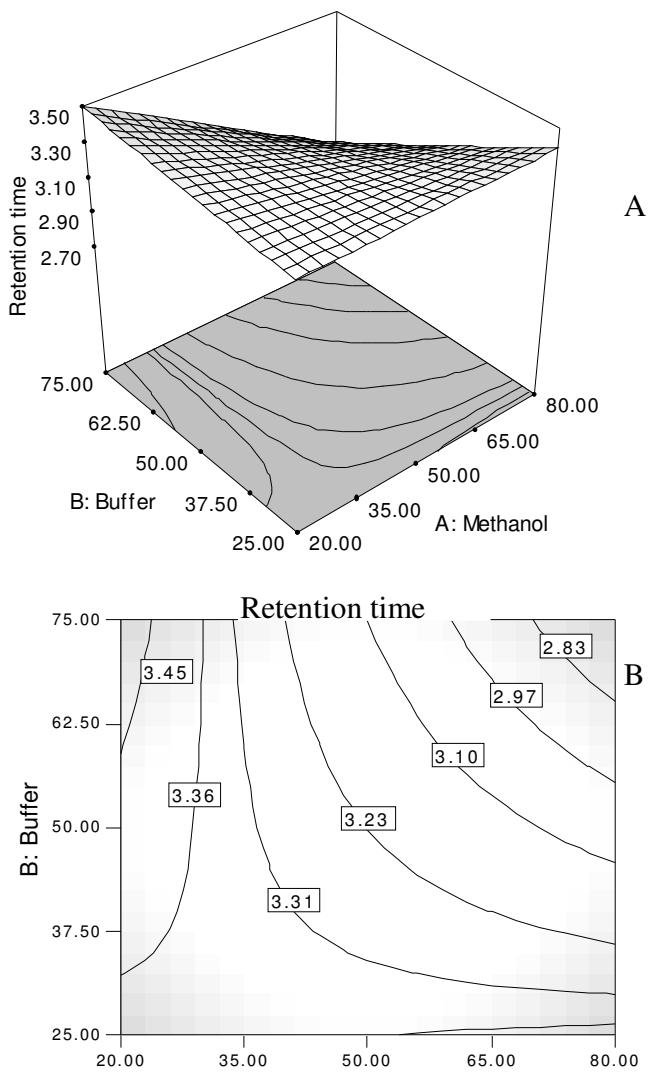

A: Methanol

Figure 2(A). 3-D plot and (B) Contour plot showing the influence of percentage of methanol in the organic phase and proportion of buffer in the mobile phase on the retention time

The combined influence of $\mathrm{X}_{2}$ and $\mathrm{X}_{3}$ on $\mathrm{Y}_{1}$ is shown by the 3-dimensional plot represented in Figure 3A. The pattern of the contours (Figure 3B) reflects a significant interaction between the two variables analyzed, particularly at higher $\mathrm{pH}$ values. The plots clearly indicate that the goals set for the retention time can be achieved at any point in the experimental domain.

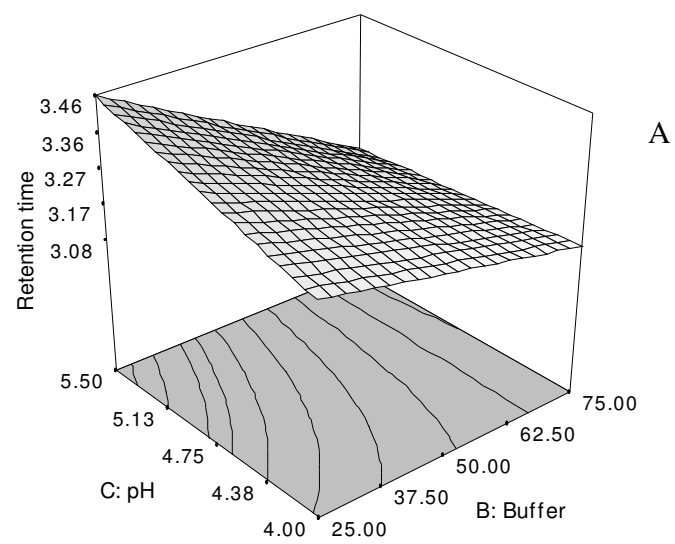




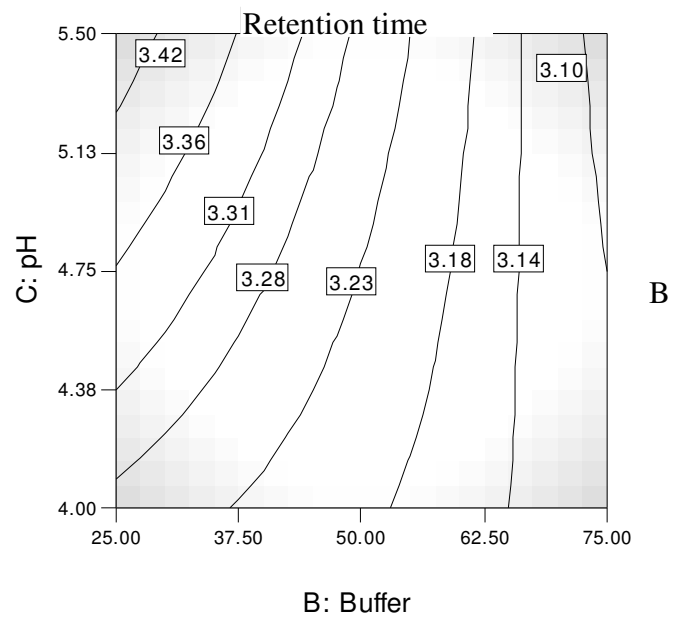

Figure 3(A). 3-D plot and (B) Contour plot showing the influence of proportion of buffer in the mobile phase and the $\mathrm{pH}$ of the mobile phase on the retention time

On the $\log _{10}$ (Tailing Factor) $\left(\log _{10} \mathrm{Y}_{2}\right)$, the $\mathrm{F}$ test with a very low probability $(\mathrm{P}>\mathrm{F}=$ 0.0028) demonstrated a high significance for the polynomial model. The value of the determination coefficient $\left(\mathrm{R}^{2}=0.9989\right)$ was found to be a good match with the adjusted determination coefficient (adjusted $\mathrm{R}^{2}=0.9960$ ), which established the high significance of the model. A relatively low value of relative standard deviation $(\% \mathrm{RSD}=4.50)$ suggested improved precision and reliability of the experiments performed. The predictor model generated for $\log _{10}$ (Tailing Factor) indicated that the proportion of buffer in the mobile phase $(\mathrm{P}>\mathrm{F}=0.0013)$, the percentage of methanol in the organic phase $(\mathrm{P}>\mathrm{F}=0.0174)$ and the $\mathrm{pH}$ of the mobile phase $(\mathrm{P}>\mathrm{F}=0.0024)$, all had significant positive influence on $\log _{10} Y_{2}$. Other than the main effects, the interaction terms $X_{1} X_{2}(P>F=0.0037)$ and $X_{2} X_{3}$ $(\mathrm{P}>\mathrm{F}=0.0040)$ illustrated a significant negative influence on $\log _{10} \mathrm{Y}_{2}$.

The influence of $\mathrm{X}_{1}$ and $\mathrm{X}_{2}$ on $\log _{10} \mathrm{Y}_{2}$ is illustrated by the 3-dimensional plot represented in Figure 4A. The pattern of lines in the contour plot (Figure 4B) reveals a significant interaction between the two variables investigated particularly at higher proportions of buffer in the mobile phase. The plots clearly show that the $\log _{10}$ (Tailing Factor) can be minimized using lower proportion of buffer in the mobile phase and lower percentage of methanol in the organic phase.

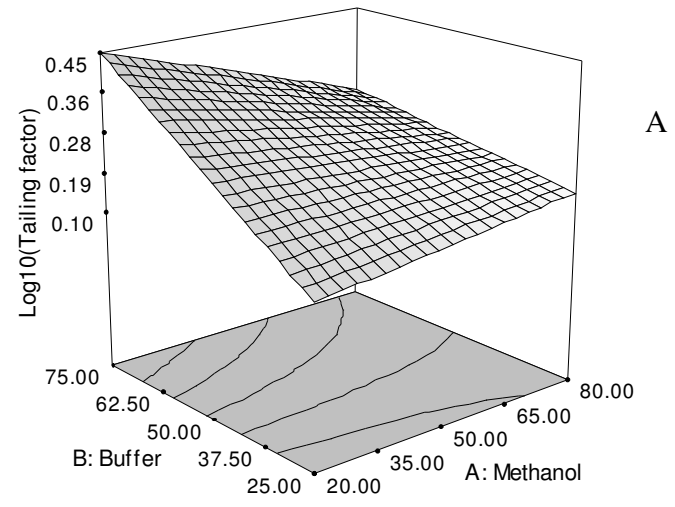




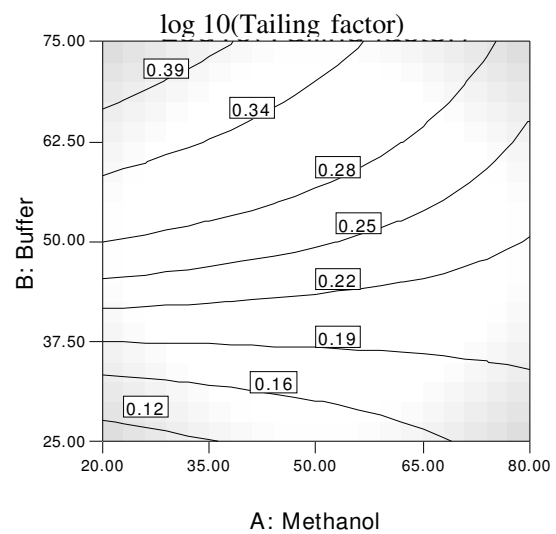

Figure 4(A). 3-D plot and (B) Contour plot showing the influence of percentage of methanol in the organic phase and proportion of buffer in the mobile phase on the $\log _{10}$ (Tailing Factor).

The influence of $\mathrm{X}_{2}$ and $\mathrm{X}_{3}$ on $\log _{10} \mathrm{Y}_{2}$ is illustrated by the 3-dimensional plot represented in Figure 5A. The pattern of lines in the contour plot Figure 5B reveals a significant interaction between the two variables particularly at higher proportions of buffer in the mobile phase. The plots clearly show that the $\log _{10}$ (Tailing Factor) can be minimized using lower proportion of buffer in the mobile phase at higher $\mathrm{pH}$ value.

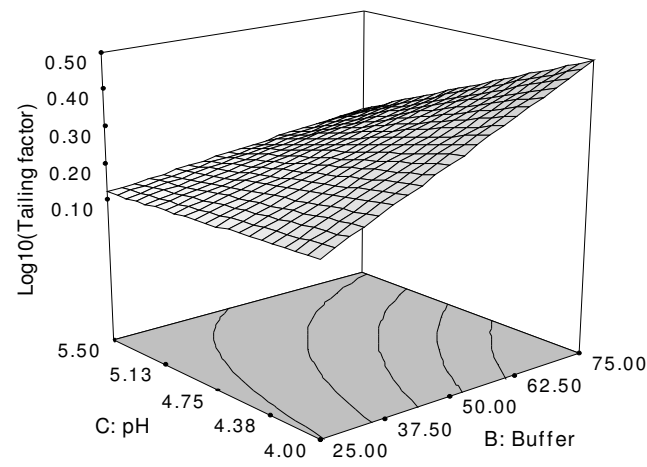

A

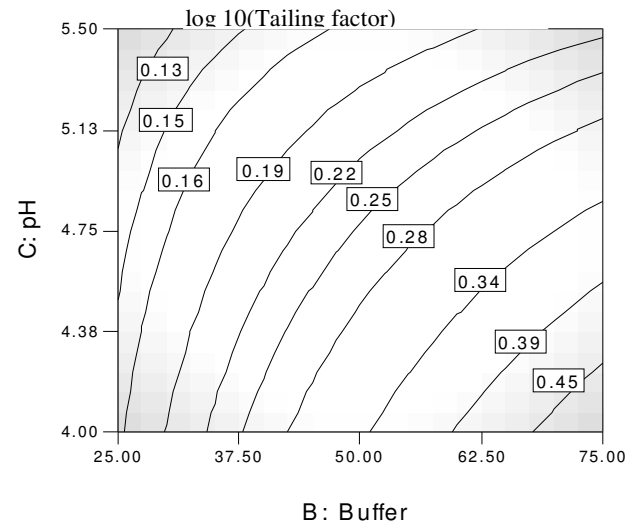

B

Figure 5(A). 3-D plot and (B) Contour plot showing the influence of proportion of buffer in the mobile phase and the $\mathrm{pH}$ of the mobile phase on the $\log _{10}$ (Tailing Factor). 
The optimum chromatographic conditions were predicted using the desirability function. Extensive grid searches performed within the experimental domain suggested a few checkpoints. The first few with a predicted overall desirability function (D) of 0.996 to 0.977 were found to have almost the same composition as that of the experimental run R5 The next checkpoint $(\mathrm{D}=0.949)$ that differed in composition from the model experimental runs was considered for further method validation. The chromatographic conditions as well as the predicted and experimental values of the response parameters are represented in Table 5. The experimental values recorded for the optimum chromatographic conditions were found to agree with those predicted by the mathematical model. The \%prediction error for the response parameters was found to range from -8.53 to 0.58 which prove the validity of the mathematical models generated by ANOVA and regressional analysis ${ }^{21}$.

Table 5. Optimum chromatographic conditions and comparison of the experimental and predicted values of the responses

\begin{tabular}{ccccc}
\hline $\begin{array}{c}\text { Composition } \\
\left(\mathrm{X}_{1}: \mathrm{X}_{2}: \mathrm{X}_{3}\right)\end{array}$ & Responses & $\begin{array}{c}\text { Predicted } \\
\text { value }\end{array}$ & $\begin{array}{c}\text { Experimental } \\
\text { value }\end{array}$ & $\begin{array}{c}\text { \% Prediction } \\
\text { error }\end{array}$ \\
\hline $40.66: 25: 5.5$ & $\mathrm{Y}_{1}$ & 3.45 & 3.43 & 0.58 \\
& $\mathrm{Y}_{2}$ & 1.29 & 1.4 & -8.53 \\
\hline
\end{tabular}

\section{Linearity}

Calibration curves were constructed using three series of standard venlafaxine hydrochloride solutions in the range of $1.0-50.0 \mu \mathrm{g} / \mathrm{mL}$. The equation of linear regression and statistical data are presented in Table 6 . The linearity of the calibration curve was validated by the high value of the correlation coefficient.

\section{Limit of detection (LOD) and limit of quantification}

In the present study, the LOD and LOQ were calculated according to the $3.3 \mathrm{\sigma} / \mathrm{s}$ and $10 \mathrm{\sigma} / \mathrm{s}$ criterions, respectively; where $\sigma$ is the standard deviation of $y$-intercepts of regression lines and $s$ is the slope of the corresponding calibration curve ${ }^{22}$. The LOD and LOQ values were found to be 0.568 and $1.72 \mu \mathrm{g} / \mathrm{mL}$ respectively.

Table 6. Statistical data of calibration curves of venlafaxine hydrochloride.

\begin{tabular}{lc}
\hline Parameters & Venlafaxine hydrochloride \\
\hline Linearity & $1-50 \mu \mathrm{g} / \mathrm{mL}$ \\
Regression equation & $Y=377048 X+558736$ \\
Standard deviation of slope & 10538.61 \\
Relative standard deviation of slope, $\%$ & 2.795 \\
Standard deviation of intercept & 64855.76 \\
Correlation coefficient $(\mathrm{r})$ & 0.9992 \\
Limit of Detection, LOD, $\mu \mathrm{g} / \mathrm{mL}$ & $0.568 \mu \mathrm{g} / \mathrm{mL}$ \\
Limit of Quantitation, $\mathrm{LOQ}, \mu \mathrm{g} / \mathrm{mL}$ & $1.72 \mu \mathrm{g} / \mathrm{mL}$ \\
\hline
\end{tabular}

\section{Accuracy and precision}

The precision was determined by analyzing three samples of venlafaxine hydrochloride at $1.0,10.0$ and $50.0 \mu \mathrm{g} / \mathrm{mL}$ on three separate days. Intra-day and inter-day data are given in Table 7. The intra-day and inter-day variability showed RSD values less than $1.4 \%$ in all three selected concentrations indicating good repeatability over the entire concentration range, which revealed that the proposed method was precise. 
Table 7. Precision of method for determination of venlafaxine hydrochloride $(n=9$; Three sets for 3d)

\begin{tabular}{cccc}
\hline Concentration Added, $\mu \mathrm{g} / \mathrm{mL}$ & Concentration found mean \pm S.D, $\mu \mathrm{g} / \mathrm{mL}$ & R.S.D, $\%$ & S.E.M \\
\hline Intra-day $(\mathrm{n}=3)$ & & & \\
1.0 & $0.991 \pm 0.001$ & 0.100 & 0.0005 \\
10.0 & $9.152 \pm 0.015$ & 0.164 & 0.009 \\
50.0 & $49.56 \pm 0.026$ & 0.052 & 0.015 \\
Inter-day $(\mathrm{n}=9)$ & & & \\
1.0 & $0.983 \pm 0.007$ & 0.712 & 0.002 \\
10.0 & $9.058 \pm 0.093$ & 1.027 & 0.031 \\
50.0 & $49.58 \pm 0.025$ & 0.050 & 0.017 \\
\hline
\end{tabular}

The accuracy of the method was checked by recovery study using standard addition method at three different concentration levels, i.e., multilevel recovery study. The preanalyzed samples were spiked with extra 50 and $100 \%$ of the standard venlafaxine hydrochloride and the mixtures were analyzed by proposed method. Recovery of standard drugs added was found to be $99.4-100.4 \%$ with the value of \%RSD less than 1.0 indicating that the proposed method was accurate. Results of recovery study are shown in Table 8.

Table 8. Recovery data for the proposed RP-HPLC method $(n=5)$.

\begin{tabular}{|c|c|c|c|c|c|}
\hline Drug & Level & $\begin{array}{l}\text { Amount of sample } \\
\text { taken, } \mu \mathrm{g} / \mathrm{mL}\end{array}$ & $\begin{array}{l}\text { Amount of standarc } \\
\text { recovered, } \mu \mathrm{g} / \mathrm{mL}\end{array}$ & $\begin{array}{c}\text { Recovery, } \\
\%\end{array}$ & $\begin{array}{c}\text { R.S.D, } \\
\%\end{array}$ \\
\hline Venlafaxine & I & 10 & 4.97 & 99.4 & 0.94 \\
\hline hydrochloride & II & 10 & 10.04 & 100.4 & 0.99 \\
\hline
\end{tabular}

\section{Robustness}

Influences of small changes in the mobile phase composition $( \pm 10 \%)$ and flow rate $( \pm 10 \%)$ were studied to determine robustness of the method. Peak areas and retention time changes were observed. Peak area values and retention time values are varied by less than $\pm 1.39 \%$ and $<0.73 \%$ respectively. Despite the changes in retention time there was no problem for quantification. The results are summarized in Tables 9 and 10 .

Table 9. The influence of small changes in mobile-phase composition (Method Robustness)

\begin{tabular}{ccc}
\hline Mobile-phase composition & $\mathrm{t}_{\mathrm{R}}$ & Peak area \\
\hline Acetonitrile-buffer-methanol (42:25:33) & 3.45 & 3814812 \\
Acetonitrile-buffer-methanol (45:25: 30) & 3.43 & 3806904 \\
Acetonitrile-buffer-methanol (48:25:27) & 3.40 & 3902839 \\
\hline
\end{tabular}

Table 10. The influence of small changes in flow rate (Method Robustness).

\section{Specificity}

\begin{tabular}{ccc}
\hline $\begin{array}{c}\text { Flow rate, } \\
\mathrm{mL} / \mathrm{min}\end{array}$ & $\mathrm{t}_{\mathrm{R}}$ & Peak area \\
\hline 0.9 & 3.76 & 4368741 \\
1.0 & 3.43 & 3906904 \\
1.1 & 3.09 & 3596917 \\
\hline
\end{tabular}

The specificity test of the proposed method demonstrated that the excipients from marketed capsules and tablets prepared in the laboratory did not interfere in the drug peak. Furthermore, well-resolved peaks indicate the specificity of the method Figure 6. 

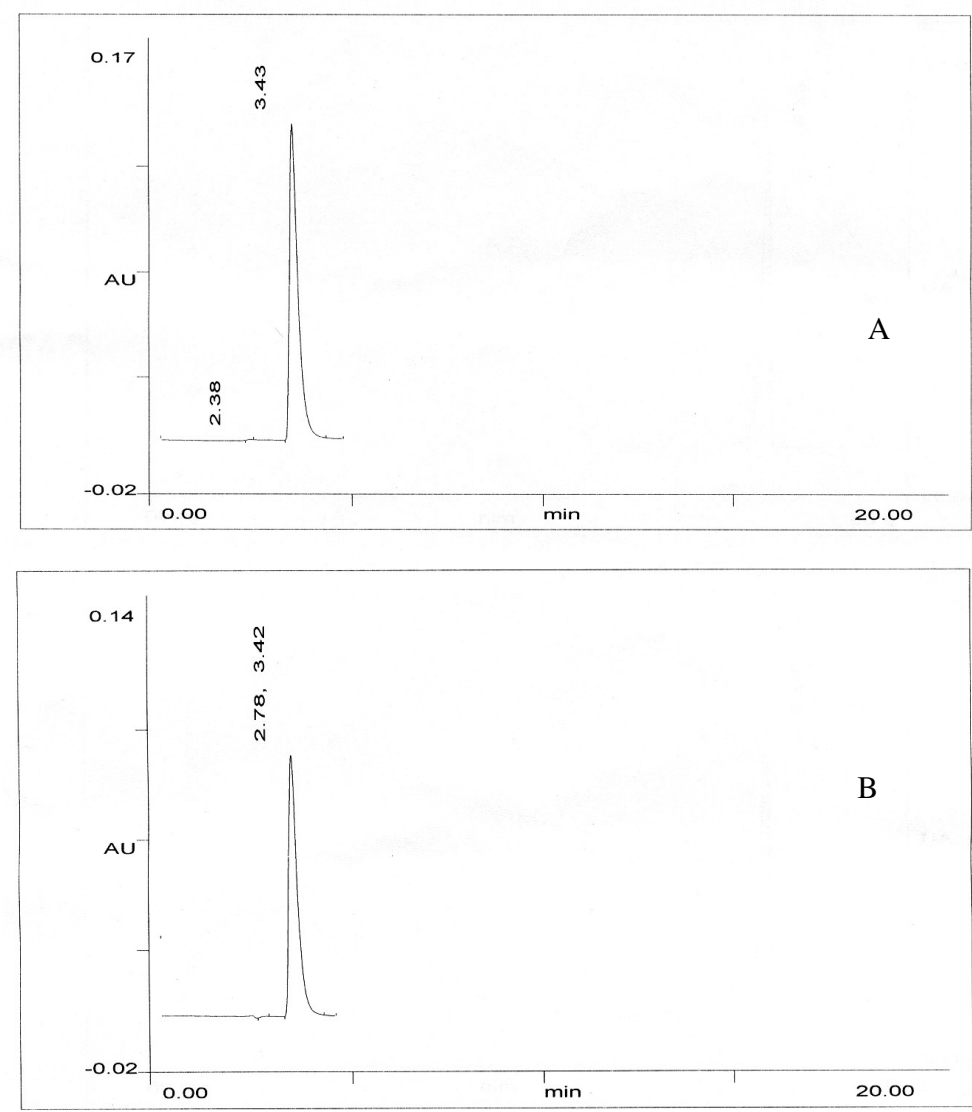

Figure 6. (A) Chromatograms of venlafaxine hydrochloride standard solution $(30 \mu \mathrm{g} / \mathrm{mL})$ and (B) Venlafaxine hydrochloride extracted from VENLOR XR-75 capsules.

\section{Assay of venlafaxine hydrochloride in dosage forms}

The developed method was applied to assay venlafaxine hydrochloride in marketed capsules and tablets prepared in the laboratory. The content was calculated as an average of five determinations and the experimental results are given in Table 11. The results were very close to each other as well as to the label value of commercial capsules and prepared tablets. Recoveries were very close to $100 \%$, which proved the suitability and accuracy of the proposed method.

Table 11. Analysis of venlafaxine hydrochloride from pharmaceutical formulations by proposed method.

\begin{tabular}{cccc}
\hline Formulations & $\begin{array}{c}\text { Labeled amount, } \mathrm{mg} \\
\text { venlafaxine }\end{array}$ & $\begin{array}{c}\text { Amount found, mg } \\
\text { venlafaxine }\end{array}$ & Assay\% \pm R.S.D, \% \\
\hline $\begin{array}{c}\text { VENLOR } \\
\text { capsules }\end{array}$ & 37.5 & 37.48 & $99.95 \pm 0.49$ \\
$\begin{array}{c}\text { VENLIFT } \\
\text { capsules }\end{array}$ & 75 & 74.60 & $99.47 \pm 0.34$ \\
Tablets & 25 & 25.03 & $100.12 \pm 0.37$ \\
\hline
\end{tabular}




\section{Conclusion}

The proposed HPLC method developed using a $2^{3}$ factorial design and optimized by employing the desirability approach provides a simple, accurate and reproducible quantitative method for routine analysis of venlafaxine hydrochloride in bulk and pharmaceutical formulations. The major advantage of this method is the quick sample analysis without prior separation or purification. Sample preparation procedure was simple with a short chromatographic time making the method suitable for processing multiple samples in a limited period of time. Finally, no pharmacopeial method has been reported yet though a couple of published methods for determination of venlafaxine hydrochloride in pharmaceutical dosage forms have been reported. It can be concluded that the proposed method is useful and suitable for routine quality control tests such as content uniformity of commercial formulations of venlafaxine hydrochloride.

\section{Acknowledgements}

Authors are thankful to Dr. B.G.Desai, Director, KLES College of Pharmacy, Bangalore for providing necessary research facilities.

\section{References}

1. Muth E A, Haskins J T, Moyer J A, Husbands G E, Neilsen S T and Sigg E B, Biochem Pharmacol., 1986, 35, 4493-4497.

2. Oliver J S, Burrows G D and Norwood T R, CNS Drugs, 2001, 15, 941-954.

3. Muth E A, Haskins J T, Moyer J A and Sigg E B, Eur J Pharmacol., 1985, 115, 139-146.

4. Schweitzer E, Weise C, Clary C, Fox I and Rickels K, J Clin Psychopharmacol., 1991, 11, 233-236.

5. Andrews J M, Ninan P T and Nemeroff C B, Depression, 1996, 4, 42-56.

6. Pento J, Drugs of the Future, 1988, 13, 839-840.

7. Mandrioli R, Mercolini L, Cesta R, Fanali S, Amore M and Raggi M A, $J$ Chromatogr B., 2007, 856(1-2), 88-94.

8. Liu W, Wang F and Li H, J Chromatogr B., 2007, 850(1-2), 183-189.

9. Ebenezer B, Asafu-Adjaye, Faustino P J, Tawakkul M A, Anderson L W, Yu L X, Kwon H and Volpe D A, J Pharm Biomed Analysis, 2007, 43(5), 1854-1859.

10. Kirchherr H and Kuhn-velten W N, J Chromatogr B., 2006, 843(1), 100-113.

11. Juan H, Zhiling Z and Huande L, J Chromatogr B., 2005, 820(1), 33-39.

12. Waschgler R, Moll W, Konig P and Conca A, Int J Clin Pharmacol Ther., 2004, 42, 724-728.

13. Raut B B, Kolte B L, Deo A A, Bagool M A and Shinde D B, J Liq Chromatogr Rel Technol., 2003, 26(8), 1297-1313.

14. Frahnert C, Rao M L and Grasmader K, J Chromatogr B., 2003, 794(1), 35-47.

15. Rao N R and Raju N A, J Sep Sci., 2006, 29(18), 2733-2744.

16. Makhija S N and Vavia P R, J Pharm Biomed Analysis, 2002, 28, 1055-1059.

17. Lima J L F C, Loo D V, Delerue-Matos C and Roque da Silva A S, IL Farmaco, 1999, 54 (3), 145-148.

18. Sethi P D, High Performance Liquid Chromatography-Quantitative analysis of Pharmaceutical Formulations, ${ }^{\text {st }}$ Ed., CBS Publishers \& Distributors, New Delhi, India, 2001.

19. Anderson M J and Whitcomb P J, DOE Simplified-Practical tools for effective experimentation, Productivity Press, New York, NY, USA, 2005.

20. Prakobvaitayakit M and Nimmanit U, AAPSPharmSciTech., 2003, 4(4), Article 71.

21. Wayne W D, Biostatistics:Analysis in Health Sciences, $5^{\text {th }}$ Ed., John Wiley \& Sons, New York, 1991.

22. ICH-Q2B Validation of Analytical Procedures: Methodology International Conference on Harmonization of Technical Requirements for Registration of Pharmaceuticals for Human Use, Geneva, Switzerland, 1996. 


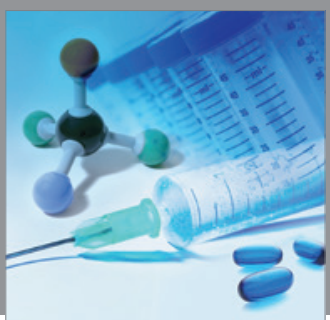

International Journal of

Medicinal Chemistry

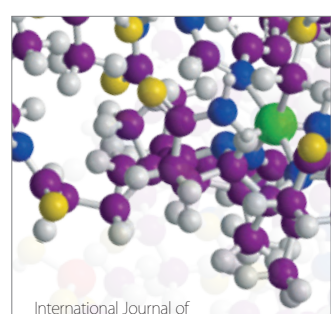

Carbohydrate Chemistry

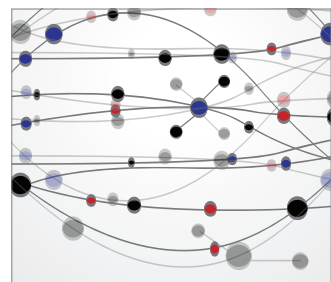

The Scientific World Journal
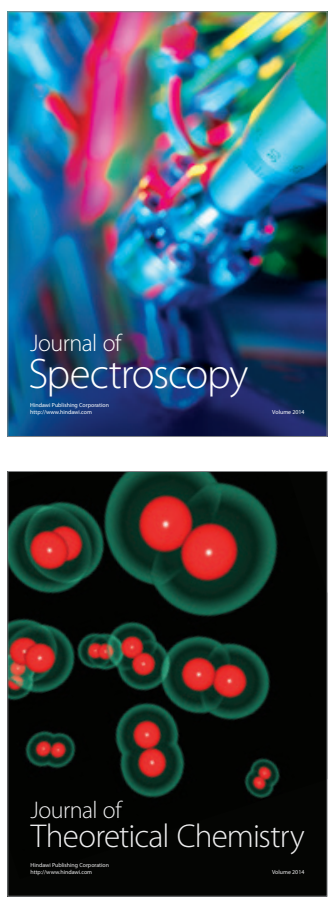
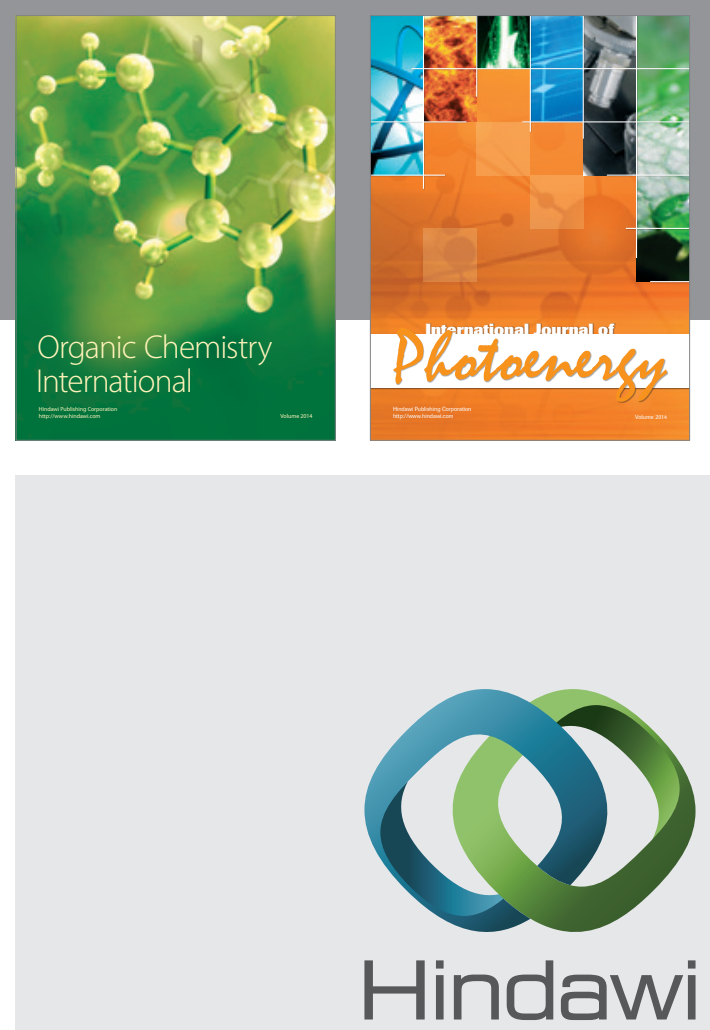

Submit your manuscripts at

http://www.hindawi.com
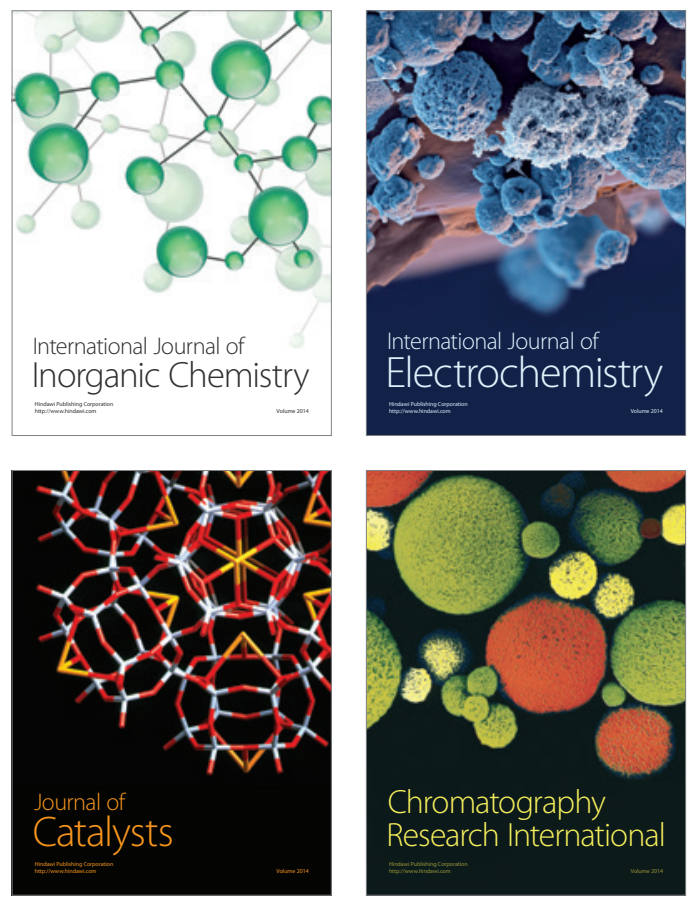
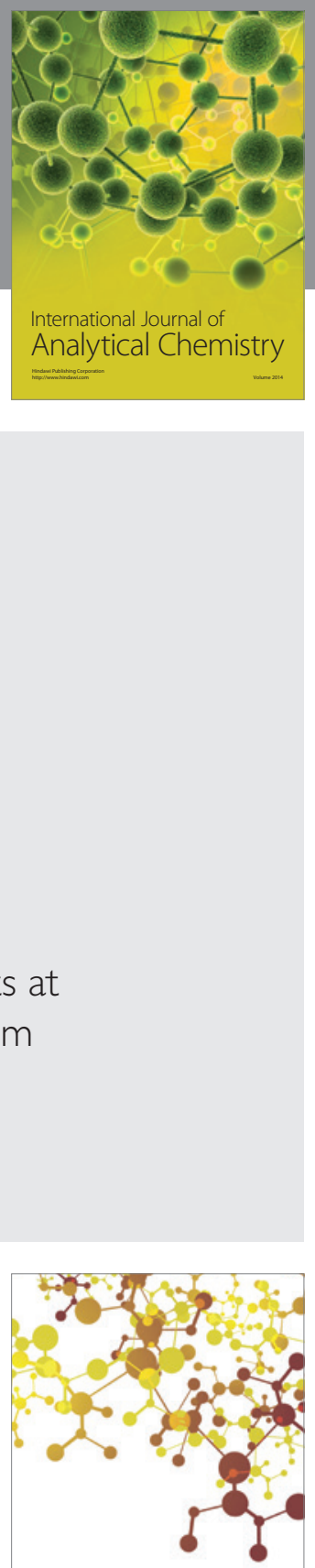

Journal of

Applied Chemistry
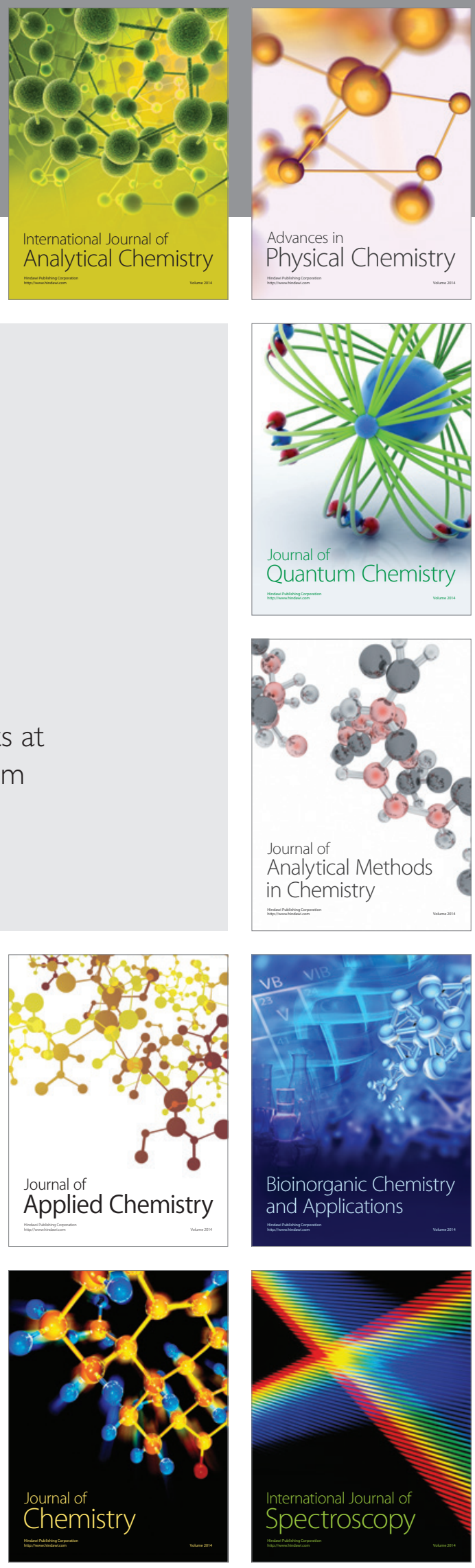